\title{
Perinatal Medicine Topics in Japan
}

\section{Kazuo Maeda*}

Department of Obstetrics and Gynecology (Emeritus), Tottori University Medical School, Yonago, Japan

\section{Perinatal Mortality in 22 Weeks or more of Pregnancy}

Official perinatal mortality in 22 weeks or more pregnancy is estimated by the following equation; (an estimated perinatal mortality in 22 weeks or more of pregnancy in 1,000 births $)=($ official maternal mortality in 100,000 births $) \times 1.03+0.17\left(\mathrm{R}^{2}=0.94, \mathrm{p}<0.001\right)$, when no official perinatal mortality was published in Japan [1]. Thus, an estimated perinatal mortality was 423 in 1899 when the official maternal mortality was 409 . A perinatal mortality in 28 or more weeks of pregnancy is estimated by $\log$ (estimated perinatal mortality) $=0.7826$ $\times \log$ (official maternal mortality) +0.08 [2], where estimated 28 weeks or more perinatal mortality was 135 in 1899 , of which difference to 22 weeks ormore mortality was 288 , i.e. estimatedperinatal mortality in 22 or more weeks of pregnancy in 1899 was 3.1 times large of estimated 28 weeks or more weeks of pregnancy. The official perinatal mortality was 21.6 in 1979 , and it was 1.7 times large of official perinatal mortality in 28 weeks or more of pregnancy, which was 12.6 , i.e. the ratio of perinatal mortality in 22 or more weeksto 28 weeks reducedby the progress of neonatal managements, particularly in neonatal intensive care units (NICU), e.g. $60 \%$ of 400 to $500 \mathrm{~g}$ birth weight infants survived in 19841999 in the NICU of Tokyo Women's Medical College, and a European neonatologist was surprised by the high survival rate in small preterm neonates [3].

\section{The Correlation of Maternal and Neonatal Mortalities}

Two variables are independent in perinatal medicine, which are maternal and neonatal mortalities, i.e. they were reported separately since 1899, for 111 years, in official perinatal reports in Japan, where mother's health was guarded in Obstetrics, Gynecology and General Medicine, whereas infantile life has been guaranteed in Pediatrics and Neonatology. The place of births was the home before 1950, and it was hospitals or obstetric private clinics after 1960 in almost 100\% pregnant women. Obstetricians were responsible for the fetal wellness, and neonatologists particularly those of NICU were responsible to the neonatal survival and heath. The neonatal mortality was the rate of neonatal deaths in 1,000 live births, and maternal mortality was maternal death rate in 100,000 total births, perinatal mortalities were rates of stillbirths andearly neonatal deaths in 22 weeks and 28 weeks or more weeks of pregnancy.

Since mother and babies spend their lives in similar social and medicalenvironments in the pregnancy, labor and delivery, correlations of various perinatal mortalities to maternal mortalities were studied in every 5 years, where close correlations were noted between some mortalities and maternal mortality, which were used in the estimation of perinatal mortalities in the years of no official report on perinatal mortality, while the author was surprised by the close correlation of maternal and neonatal mortalities, which were scientifically independent variables; where (the neonatal mortality in 1,000 live births $)=($ Maternal mortality in 100.000 births $) \times 0.21-1.26, \mathrm{R}^{2}=0.97$, and $\mathrm{p}<0.001[3]$. Does the correlation mean originally close bonding of mother and child?

\section{References}

1. Kamiya K (2012) Maternal and child health statistics of Japan, 2011. Mothers \& Children's Health Organization, Tokyo, Japan.

2. Maeda K (1966) Estimation of perinatal mortalities in the world's countries from maternal mortalities. J Maternal-Fetal Med 5: 132-136.

3. Maeda K (2014) A miracle in mortalities of perinatal medicine in Japan. J Healt Med Informat, in press.
*Corresponding author: Kazuo Maeda, Department of Obstetrics and Gynecology (Emeritus), Tottori University Medical School, Yonago, Japan, Tel: 81-859-22-6856; Fax: 81-859-22-6856; E-mail: maeda@mocha.ocn.ne.jp

Received March 15, 2014; Accepted March 16, 2014; Published March 22, 2014

Citation: Maeda K (2014) Perinatal Medicine Topics in Japan. J Health Med Informat 5: e128. doi:10.4172/2157-7420.1000e128

Copyright: (c) 2014 Maeda K. This is an open-access article distributed under the terms of the Creative Commons Attribution License, which permits unrestricted use, distribution, and reproduction in any medium, provided the original author and source are credited. 